\title{
Any good vibrations with bogie tracks?
}

\begin{abstract}
A four-wheeled forestry machine is quite jumpy to ride on in uneven terrain. To overcome that problem Nordic forestry are often with 8 wheels and often the wheels are placed in a bogie construction, which means all wheels are powered. To improve traction bogie tracks has been used both to get better grip but also to minimize soil damage. These tracks are often made of steel and could mean a rather bumpy travelling. The question is it really so?

Four paths were used three times, going upwards and downhill, with the variables wheels, bogie tracks, \pm 15 ton load, tested on an eight-wheeled 20 tons forwarder both on driver seat and cabin floor. The vibrations decreased and most with load. Thus bogie tracks from Olofsfors improve traction, decrease fuel consumption on soft ground and decrease vibrations
\end{abstract}

Keywords: forestry machine, bogie tracks, soft ground, fuel consumption, timber, steel tracks, rehn's dissertation
Volume 2 Issue I - 2018

\author{
Bygdén G, Burström L,Wästerlund I \\ Olasgarden Forest \& Roads, Solvägen, Sweden
}

Correspondence: Iwan Wästerlund, Olasgarden Forest \& Roads, Solvägen 9,918 32 Sävar, Sweden, Email iwanolasgarden@telia.com

Received: December 19, 2017 | Published: January 17, 2018

\section{Introduction}

Forestry machines are often travelling on unprepared terrain, which means often rather bumpy ride.4-wheeled machines became 6-wheeled and later on 8 wheeled machines to alleviate the worst obstacles. Nordic forestry people discovered if these wheels were arranged in bogie construction the machine (usually a forwarder that could carry timber) both could better negotiate obstacles and with all wheels driven one could get better climbing ability. Still machines could get stuck uphill in a snowy terrain. One way to improve traction was to put steel tracks on the wheels and there we are today. One of the bigger producers of bogie tracks in the world is Olofsfors in Northern Sweden. These tracks are of special steel to last when driving on stones and sand. Steel tracks on stony terrain must mean a bumpy ride for the operator many people are thinking. That is why we decided to test that opinion and Rehn's dissertation (2004, R.M.S. values that allowed driving 2.5-3.1h/day according to the ISO 2631-1 standard) showed that compared to snowmobiles and snow groomers, forwarder drivers belonged to those with most musculoskeletal disorders due to whole-body vibration exposure. In his study the forestry machines had no bogie tracks.

\section{Aim}

The aim was to compare vibrations in the cabin floor and the chair in a forwarder with wheels on the same forwarder with bogie tracks on the same wheels when it was empty and \pm loaded with 15 tonnes of timber.

\section{Material and method}

A 20tons 8-wheeled Valmet 890.2 was used as test vehicle with $180 \mathrm{~kW}$ engine and hydrostatic all- wheel drive (powerful enough to drive $30 \mathrm{~km} / \mathrm{h}$ in uneven terrain). The wheeled version had Nokian King tyres with 5,5bars inflation pressure which is the recommended pressure for this type of machine. The load space was LoadFlex with in-folded stakes, which means up-right stakes and a rather high load and possibly higher vibrations. 4 sets of EcoMax tracks were put on the machine for the tracked version, which added 4.8tonnes weight to the machine but increased vehicle stability due to lowered centre of gravity. To load the machine 15 tonnes of timber was prepared the day before using the built in scales in the banks $( \pm 10 \mathrm{~kg})$ (Figure 1).

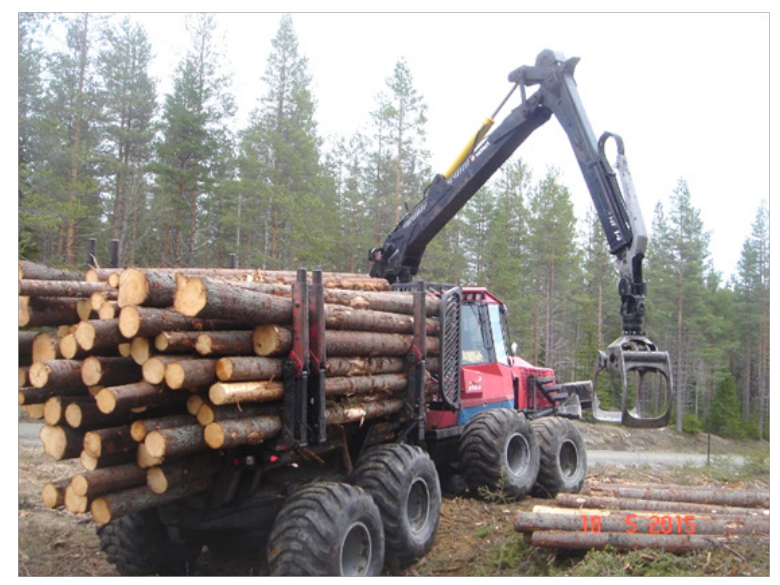

Figure I The test vehicle,Valmet 890.2 with load but no bogie tracks.

The test area was a newly cut slope sloping 8 degrees gently sloping in one direction towards north. It was a gravelly till slope with Myrtillus and Vaccinium vegetation but small stones were mainly in the ground and thus not an obstacle for the vehicle. Moisture content was $30 \%$ (dry measured), but since it was a gravelly soil this amount of water in the soil had minor effect on rutting (No ruts afterwards). The machine was driving on a new passage for each trial that was about $70 \mathrm{~m}$ long (from start to stop, measured with a ruler). Each trial was driven 3times (up-down-up) and each passage was clocked. Only one problem occurred and without tracks but with load some slippage occurred but once rolling the machine came up. Measurements were done according to International standard ISO 2631-1 on both driver seat and at the floor in the cabin of the forwarder near where the chair attachment. This sensor on the floor was loaded with a bag of $1 \mathrm{~kg}$. Vibrations at each point were measured in $\mathrm{X}, \mathrm{Y}$ and $\mathrm{Z}$ simultaneously with two Larson Davis Human Vibration Monitor HMV100 with belonging measurement plate Dytran5313A. Measurement equipment was controlled with a calibrator (Brüel \& Kjær 4294) before and after measurements (Figure 2). 


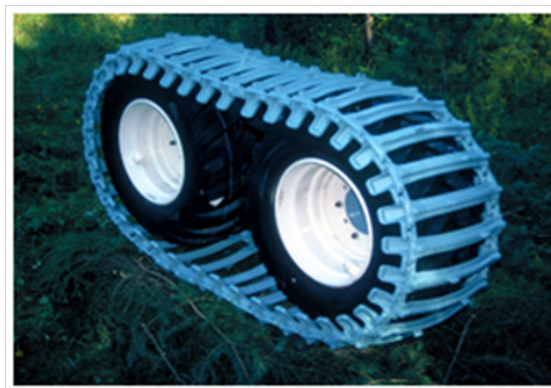

Figure 2 EcoTracks bogie band from Olofsfors.

\section{Results}

In summary: Tracks reduce vibrations significantly in the chair and cabin floor in front of the seat. Load reduced significantly and speeds influenced the vibrations in the chair. Compared with older studies of ordinary forwarder ${ }^{1}$ the reductions are remarkable and more than $50 \%$ and with bogie tracks the reduction was $95 \%$, especially in the Y-direction. Analysed in SAS with generalised modelling it was found that the $\mathrm{P}$-value for tracks was $\mathrm{p}=0.5$ on the cabin floor. For the whole model $\mathrm{F}=0.112$ especially with load (Table 1) (Table 2) (Figure 3 ). Thus the machine became more stable and less vibrating supplied with bogey tracks.

Table I Summary of exposure measurements made in the forwarder

\begin{tabular}{|c|c|c|c|c|c|c|c|c|c|c|c|c|c|c|c|c|c|}
\hline \multirow[b]{2}{*}{ Case } & \multirow[b]{2}{*}{$\begin{array}{l}\text { Track } \\
\text { no }\end{array}$} & \multirow[b]{2}{*}{ rpm } & \multirow[b]{2}{*}{$\begin{array}{l}\text { Length } \\
\text { (m) }\end{array}$} & \multicolumn{4}{|c|}{$\begin{array}{l}\text { Time } \\
\text { (minutes) }\end{array}$} & \multicolumn{3}{|c|}{$\begin{array}{l}\text { Speed } \\
(\mathrm{m} / \mathrm{min})\end{array}$} & \multicolumn{3}{|c|}{$\begin{array}{l}\text { Chair. } \\
\text { X-direction } \\
\left(\mathrm{m} / \mathrm{s}^{2}\right)\end{array}$} & \multicolumn{3}{|c|}{ Floor } & \multirow[b]{2}{*}{$\begin{array}{l}\text { SumXYZ } \\
\left(\mathrm{m}^{\prime} \mathrm{s}^{2}\right)\end{array}$} \\
\hline & & & & $U_{p}$ & Down & $U_{p}$ & $\begin{array}{l}\text { Load } \\
\text { (ton) }\end{array}$ & $U_{p}$ & Down & Up & $U_{p}$ & Down & $U_{p}$ & Up & Down & $U_{p}$ & \\
\hline $\begin{array}{l}\text { Wheel. } \\
\text { 0-load }\end{array}$ & 7 & 1550 & 67.2 & 2.47 & 1.569 & 2.06 & 22.0 & 24.1 & 34.5 & 32 & 0.35 & 0.36 & 0.38 & 0.23 & 0.24 & 0.29 & 0.53 \\
\hline $\begin{array}{l}\text { Wheel, } \\
\text { +-load }\end{array}$ & 4 & 1550 & 74.3 & 3.21 & 2.304 & 2.17 & 35.0 & 22.6 & 33.8 & 31.6 & 0.3 & 0.34 & 0.38 & 0.21 & 0.23 & 0.27 & 0.44 \\
\hline $\begin{array}{l}\text { E-max, } \\
\text { 0-load }\end{array}$ & 5 & 1220 & 72.3 & 2.27 & 2.32 & 2.28 & 24.9 & 32.5 & 28.9 & 28.9 & 0.36 & 0.31 & 0.36 & 0.23 & 0.23 & 0.24 & 0.49 \\
\hline $\begin{array}{l}\text { E-max, } \\
\text { +-load }\end{array}$ & 2 & 1220 & 78.6 & 3.03 & 3.12 & 2.54 & 39.9 & 26.1 & 24.6 & 27.1 & 0.27 & 0.25 & 0.22 & 0.15 & 0.17 & 0.14 & 0.32 \\
\hline
\end{tabular}

Table 2 Average values of measured exposure levels in three directions as well as the sum of them and 0 loads means no timber on the forwarder

\begin{tabular}{llllll}
\hline & & X-direction & Y-direction & Z-direction & Sum \\
\hline Case & Meas. place & $\left(\mathrm{m} / \mathrm{s}^{2}\right)$ & $\left(\mathrm{m} / \mathrm{s}^{2}\right)$ & $\left(\mathrm{m} / \mathrm{s}^{2}\right)$ & $\left(\mathrm{m} / \mathrm{s}^{2}\right)$ \\
\hline Wheel, O load & Chair & 0.36 & 0.31 & 0.33 & 0.58 \\
& Floor & 0.26 & 0.27 & 0.3 & 0.48 \\
Wheel, + load & Chair & 0.34 & 0.24 & 0.28 & $0.5 \mathrm{I}$ \\
& Floor & 0.24 & 0.21 & 0.19 & 0.37 \\
Tracks, O load & Chair & 0.34 & 0.26 & 0.33 & 0.54 \\
& Floor & 0.23 & 0.24 & 0.29 & 0.44 \\
\multirow{2}{*}{ Tracks, + load } & Chair & 0.25 & 0.17 & 0.19 & 0.35 \\
& Floor & 0.15 & 0.17 & 0.18 & 0.29 \\
\hline
\end{tabular}

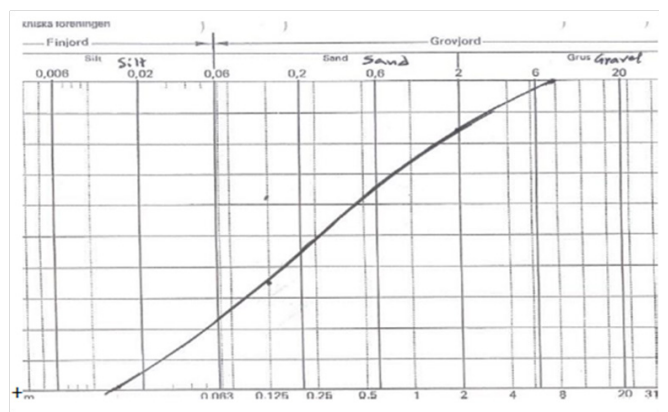

Figure 3 Sieving diagram for the test area.

\section{Conclusion}

With Olofsfors tracks like Eco Tracks, Eco Max etc. it is possible to get better support on weak terrain, ${ }^{2}$ less rolling resistance, ${ }^{3}$ and thereby less fuel consumption and now proven less vibrations in the cabin of the machine. On top of that recognised good service. Do we need more facts for buying Olofsfors bogie tracks?

\section{Acknowledgments}

None.

\section{Conflict of interest}

Authors declare that there is no conflict of interest.

\section{References}

1. Rehn B. Musculoskeletal disorders and whole-body vibrations exposure among professional drivers of all-terrain vehicles. Umeå University, Sweden; 2004. 
2. Bygdén G, Wästerlund I. The fuel consumption of forestry vehicles driving on soft ground with bogie tracks. Proceeding of the Joint 9th Asia-Pacific ISTVS Conference, Barcelona, Spain; 2010.
3. Bygdén G, Eliasson L, Wästerlund I. Rut depth, soil compaction and rolling resistance when using bogie tracks. Journal of Terra mechanics. 2003;40(3):179-190. 